\title{
USE OF 20 MINUTE WHOLE BLOOD CLOTTING TIME IN PATIENTS OF SNAKEBITE; AN EXPERIENCE FROM KOHAT, KHYBER PAKHTUNKHAH
}

\author{
Hammad Javed, Tariq Bashir*, Atif Rauf**, Syed Murtaza***, Raja Jibran**** \\ Combined Military Hospital Mangla/National University of Medical Sciences (NUMS) Pakistan, ${ }^{*}$ Combined Military Hospital Kohat/National University of \\ Medical Sciences (NUMS) Pakistan, **Armed Forces Institute of Cardiology/National University of Medical Sciences (NUMS) Rawal pindi Pakistan, \\ ${ }^{* * *}$ Combined Military Hospital Loralai/National University of Medical Sciences (NUMS) Pakistan, ${ }^{* * * * C o m b i n e d ~ M i l i t a r y ~ H o s p i t a l ~ S k a r d u / ~}$ \\ National University of Medical Sciences (NUMS) Pakistan
}

\section{ABSTRACT}

Objective: To study the diagnostic accuracy of 20-minute whole blood clotting time in hemotoxic snakebite.

Study Design: Cross sectional validation study.

Place and Duration of Study: Combined Military Hospital Kohat Pakistan, from Jul 2015 to Jun 2017.

Methodology: Study included 52 patients who presented with the complaint of a snakebite. The data were recorded on predesigned proforma including clinical, laboratory features. All the patients were kept indoor for observation for a minimum of 72 hours from the time of presentation.

Results: The study showed that males were more affected with age group between 20-50 years. Most common presenting features were local swelling $33(71 \%)$ and pain and most common snakebite type was hemotoxic $33(71 \%)$. The 20-minute whole blood clotting time was found to have low sensitivity $(61 \%)$ and specificity $(58 \%)$. A significant association was found between the dose of anti-snake venom and severity of coagulopathy $(p<0.001)$, respiratory failure $(p<0.001)$ and development of side effects due to anti snake venom $(p<0.001)$. The mortality rate was $6.5 \%$ and was significantly related to age of the victims ( $p=0.003$ ). The diagnostic accuracy of 20 -minute whole blood clotting time was $60.25 \%$.

Conclusion: The use of 20-minute whole blood clotting time can not only be misleading but also a source of delay in administering anti snake venom given the low sensitivity and specificity and high false negative rate.

Keywords: Anti snake venom, Hemotoxic, Neurotoxic, Russel viper, Snakebite, 20-minute whole blood clotting time.

How to Cite This Article: Javed H, Bashir T, Rauf A, Murtaza S, Jibran R. Use of 20 Minute Whole Blood Clotting Time in Patients of Snakebite; An Experience from Kohat, Khyber Pakhtunkhwa. Pak Armed Forces Med J 2021; 71(5): 1619-1623. doi: https://doi.org/10.51253/pafmj.v71i5.3684

This is an Open Access article distributed under the terms of the Creative Commons Attribution License (https://creativecommons.org/licenses/by-nc/4.0/), which permits unrestricted use, distribution, and reproduction in any medium, provided the original work is properly cited.

\section{INTRODUCTION}

There are more than 3000 species of snakes found worldwide however, only about 300 of them are known to be poisonous. Majority of the bites are caused by nonpoisonous snakes and are innocuous ${ }^{1}$. There are around two million snakebites occurring globally and an estimated mortality of around 100,000 deaths per year although the statistics are highly variable due to lack of accurate data and underreporting of the events ${ }^{2}$.

In Pakistan there are more than seventy species of poisonous snakes found throughout the country. Most of the reported cases are from rural areas of Sind especially the Thar Desert however snakebite cases occur all over the country ${ }^{3}$. Majority of the victims are farmers, field and plantation workers and dessert dwellers. There is great seasonal and diurnal variation in the incidence of snakebite with majority of the cases being reported in the summer and rainy seasons ${ }^{4}$.

Correspondence: Dr Hammad Javed, Department of Medicine, Combined Military Hospital, Mangal Pakistan

Received: 25 Dec 2019; revision received: 03 Jun 2020; accepted: 10 Jun 2020
In our region, there are four major snake species also known as the Big Four which include Naja naja (cobra), Daboia russellii (Russel viper), Echis carinatus (saw-scaled viper) and Bungarus ceruleus (Krait). They are all covered by the conventional polyvalent antisnake venom (ASV) commonly used in Pakistan ${ }^{5}$. However this concept is criticized as it does not cater for a significant number of poisonous snakebites caused by other species 6 .

In Pakistan very limited data is available regarding snakebite cases from Khyber Pakhtunkhwa and Baluchistan as most available studies are from Sind and a few from Punjab. In our study, we have analyzed the epidemiological, clinical, laboratory parameters of snakebite victims and the use of anti snake venom in such patients. This study which was conducted in Combined Military Hospital Kohat included patients not only from Kohat district but also from adjoining areas such as Dera Ismail Khan, Karak, Bannu, Wazirastan, Thall and Hangu.

Twenty minute whole blood clotting time (WBCT) has long been used as a bedside test to determine the need for anti snake venom (ASV) 
administration especially in resource poor settings. However this test has serious limitations owing to variable and conflicting reports about its sensitivity and specificity 7,8 . In this study we analyzed the use of $20 \mathrm{~min}$ WBCT for its sensitivity, specificity and usefulness in comparison with the conventional coagulation tests.

\section{METHODOLOGY}

The cross sectional validation study was conducted at the Combined Military Hospital (CMH) Kohat, from July 2015 to June 2017. The study was approved by institutional Ethics Review Board and informed consent was taken from the patients. In this study various epidemiological, clinical and laboratory parameters of the patients were obtained on predesigned proforma.

Inclusion Criteria: All patients presenting to the hospital with complaints of snakebite during the aforementioned period were included in the study.

Exclusion Criteria: Patients with no convincing clinical or laboratory evidence of snakebite were excluded.

The initial sample consisted of 52 patients selected via non probability consecutive sampling technique, The age, gender, occupation, time of bite (whether day, night or dawn/dusk), month of the year and time to reach hospital were recorded. Sample size was calculated by using WHO sample size calculator using 95\% confidence interval, 25\% Anticipated population proportion and $10 \%$ Absolute precision required. Upon reaching hospital and, the important clinical features including local signs (fang marks, swelling, bleeding, necrosis), locoregional (limb swelling, distal neurovascular status, compartment syndrome) and systemic features (mucosal or generalized bleeding, hematemesis, hematuria, diplopia, respiratory failure) were assessed and recorded. The location of bite on the body was noted as being on limbs, torso or face. The type of bite was ascertained on the basis of clinical and laboratory features as nonpoisonous, hemotoxic or neurotoxic. All the patients were admitted for further evaluation and management. Baseline laboratory tests including blood counts, urea, creatinine, transaminases, coagulation profile, urinalysis, ECG and chest $x$ ray were done. ABGs were done in patients with dyspnea, hypoxemia or respiratory distress. Coagulopathy was defined as INR>1.5. 20-minute WBCT was performed in each patient using about $5 \mathrm{ml}$ of whole blood. The blood was kept in a clean transparent glass test tube and observed after 20 minutes for formation of clot. Failure of blood to clot was taken as positive test.
The data were recorded on predesigned proforma. The statistical analysis was done using SPSS-20. Qualitative variables like gender, year, month and time of bite, location of bite on body, presence of complications like coagulopathy, respiratory failure and death were represented by frequencies and percentages. Mean \pm SD were calculated for quantitative variables like age. Pearson chi-square test was used for comparison between various variables. A $p$-value of $\leq 0.05$ was taken as significant.

ASV was administered if any of the following conditions were met, 1) presence of coagulopathy defined by epistaxis, hemoptysis, hematuria or malena, 2) deranged coagulation ie PT $>4$ seconds control, 3) signs of neurotoxicity including ptosis, diplopia, respiratory depression, hypoxemia or hypercarbia ${ }^{7}$.

Successful treatment of snakebite is critically dependent on timely administration of anti snake venom (ASV) as it is the only specific treatment available ${ }^{10}$. After securing $A B C$ and ensuring hemodynamic stability, anti-snake venom (ASV) was administered to patients with features suggestive of envenomation. The ASV used was liquid polyvalent ASV produced by NIH Islamabad. Pretreatment with IV steroids and antihistamines was done. ASV was administered in incremental doses of 5 vials per dose after dilution in $5 \%$ dextrose water over 1-2 hours ${ }^{11}$. Patients were kept in intensive care unit during administration of ASV to monitor for adverse effects which were classified as none, mild (not requiring adrenaline) or severe (requiring inj adrenaline). The dose of ASV was repeated at 6 hours if coagulation was still deranged. In case of neurotoxic envenomation, the repeat dose was given based on clinical assessment as both the patients were on mechanical ventilation.

An attempt to identify the species of snake was done in all cases. This was based upon visual inspection of the dead snake brought along by the patient or attendant. In 2 cases identification was based on the photographs of snake taken by mobile phone. The WHO syndromic approach of snake bite classification was employed and was found to be extremely useful12. Majority of the snake bites were caused by viper bites and the most common species was identified to be Sawscaled viper also known as Echis carinatus.

\section{RESULTS}

There were a total of 46 cases of snakebite included in the study. Majority of patients $39(84.8 \%)$ were male and $7(15.2 \%)$ were female. The mean age was $34.34 \pm 15.78$ years. Majority of patients $36(78.3 \%)$ 
were under 50 years of age. Most bites 21(45.7\%) occurred during the months of July and August. A significant proportion of bites $28(60.9 \%)$ occurred during daytime. Majority of patients $36(78.3 \%)$ reached the hospital within 24 hours of being bitten. Bites mostly occurred on limbs 44 (95.7\%) and involved head or neck region or torso in only $2(4.3 \%)$ patients.

Out of 46 patients, 10 had nonpoisonous bite $(21.7 \%), 33(71.7 \%)$ patients had hemotoxic bite and only $3(6.5 \%)$ patients had neurotoxic bite. Species identification was possible in $17(37 \%)$ cases. Of these, $16(34.8 \%)$ snakes were identified to be saw-scaled viper and only one $(2.2 \%)$ was identified to be Russel viper. Fang marks were present in $36(78.3 \%)$ patients. Swelling was the most common local feature of envenomation present in $33(71.7 \%)$ patients, other features included bleeding $10(21.7 \%)$ and gangrene $2(4.2 \%)$. Coagulopathy was present in $34(73.9 \%)$ out of which only $2(4.2 \%)$ had life threatening bleed and required transfusion. The 20 minute whole blood clotting time was positive in 26 patients. The sensitivity, specificity, positive predictive value and negative predictive value of 20 min whole blood clotting time (WBCT) are shown in table-I and II. The Receiver Operating Characteristic (ROC) curve analysis for 20 min WBCT was shown in the figure. The area under the curve (AUC) is 0.6 which indicates only moderate diagnostic accuracy.

Table-I: 20 minute whole blood clotting time and coagulopathy.

\begin{tabular}{l|c|c|c}
\multicolumn{2}{c|}{} & \multicolumn{2}{c}{ Coagulopathy } \\
\cline { 3 - 4 } \multicolumn{2}{c|}{} & Present & Absent \\
\hline \multirow{2}{*}{$\begin{array}{l}\text { Whole blood } \\
\text { clotting rime }\end{array}$} & Positive & $21(61.76 \%)$ & $5(41.66 \%)$ \\
\cline { 2 - 4 } & Negative & $13(38.23 \%)$ & $7(58.33 \%)$ \\
\hline
\end{tabular}

Table-II: Sensitivity, specificity, positive predictive value, negative predictive value and diagnostic accuracy for 20 minute whole blood clotting time.

\begin{tabular}{l|c}
\hline Diagnostic Parameters & Values \\
\hline Sensitivity & $61.76 \%$ \\
\hline Specificity & $58.3 \%$ \\
\hline Positive predictive value & $80.8 \%$ \\
\hline Negative predictive value & $35.0 \%$ \\
\hline Diagnostic accuracy & $60.25 \%$ \\
\hline
\end{tabular}

Only $3(6.5 \%)$ patients developed renal failure however, both of them recovered completely with conservative treatment. Respiratory failure occurred in $3(6.5 \%)$ patients having neurotoxic bite and had to be placed on mechanical ventilation. All were successfully weaned off and made a complete recovery.

ASV was administered to 36 patients (78.3\%) who fulfilled the criteria. Out of these, $25(78.3 \%)$ received
10 vials each, 2 received 15 vials and 7 patients received 20 vials, only one patient received 30 vials. There was a significant association between dose of ASV and severity of coagulopathy $(p<0.001)$, respiratory failure $(p<0.001)$ but not with renal failure $(p=0.234)$. Adverse affects of ASV administration were seen in 17 patients (37\%) while none suffered anaphylaxis. There was a significant association between dose of ASV and development of side effects $(p<0.001)$.

The mortality rate was $6.5 \%$ a 3 patients succumbed to the complications of hemotoxic snakebite. There was a significant association between mortality and age of the victims $(p=0.003)$, severity of coagulopathy $(p<0.001)$, and ASV dose $(p<0.001)$.

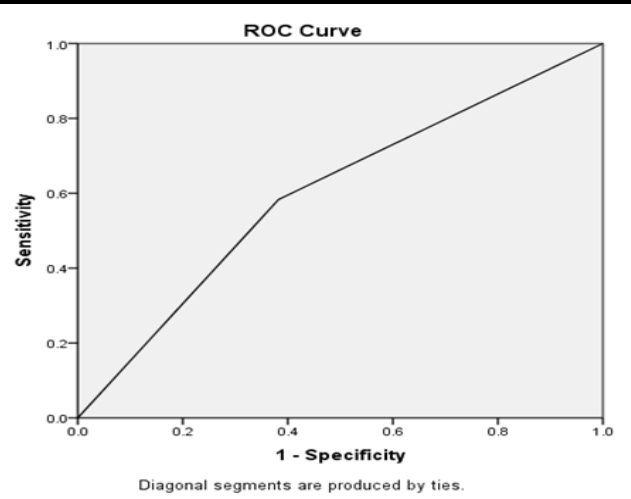

Figure-1: ROC curve for $20 \mathrm{~min}$ whole blood clotting time.

\section{DISCUSSION}

Ours was one of the pioneer studies from this region regarding snakebite management and assessing the use of much debated $20 \mathrm{~min}$ WBCT. We also undertook a detailed assessment of the use of ASV and various aspects of its administration and side effects profile. Before this, most of the published data has come from studies from certain areas of Sindh and Punjab.

Majority of the victims in our study were male $(84.8 \%)$ and belonged to the working age group ie 20 to 50 years old. In an Iranian study, $76.1 \%$ patients were male with average age $35.6 \pm 16.5$ years ${ }^{13}$. In a study by Zamani et al, the average age of victims was $28.3 \pm$ 0.36 years and their age ranged between $20-30$ years ${ }^{14}$. Thus, our study, in line with the findings of above mentioned studies, upholds the fact that males constitute the majority of victims of snakebite, mostly are under 50 years old.

In contrast to the traditional view which states that majority of the snake bites as non-venomous, the 


\section{Blood Clotting Time in Patients of Snakebite}

reverse was found to be the case in our study. This might be because of the fact that although majority of the patients seek treatment from local traditional healers, only those with poisonous bite report to hospital as they get little benefit from their treatment. This finding was also seen in a Bangladeshi study by Alam et $a^{15}$.

Majority of the bites occurred during daytime 28 (60.9\%) whereas only 14 (30.4\%) occurred at dawn or dusk indicating that working hours in the day light is the most vulnerable time. This finding is in accordance with majority of other regional studies. According to a study from Iran, majority of the bites occurred during day time ${ }^{15}$. However, another study by Rahman et al. Majority of the victims was bitten at night ${ }^{17}$. Seasonal variation in the incidence of snake bite was also observed with July and August being the most vulnerable months. In a study undertaken by Dehghani, most of the bites occurred between May and September ${ }^{16}$.

Most of the bites occurred on limbs 44 (95.7\%) especially lower limbs whereas face or torso was bitten in one case each. In a study by Alam from Bangladesh lower limb was the most commonly bitten site ${ }^{15}$. Similar findings were reported in a study from Iran by Monzavi et al ${ }^{18}$. In our study of 46 cases, 36 (78.3\%) had poisonous bites, most of whom were hemotoxic 33 $(71.7 \%)$ and only $3(6.5 \%)$ were neurotoxic. In a study from Pakistan, it was seen that of the 65 patients only $2(13 \%)$ had a neurotoxic bite. In another Pakistani study conducted in involving 74 patients, majority of the patients had hemotoxic bite ${ }^{19}$. In a study from Bangladesh, $30(60 \%)$ of the total 50 patients presenting with snake bite had venomous bites with neurotoxic being the most common type ${ }^{15}$.

20-minute WBCT has been used with variable success in different clinical settings. In a study from Africa, the test was found useful for administration of ASV in a setting where laboratory access was not readily available ${ }^{20}$. In an Indian study by Indira in 2017, 20min WBCT was utilized in a hospital setting with specially trained clinical research assistants, the maximum sensitivity was reported upto $81 \%$ potentially missing one fifth of the cases where ASV was indicated $^{21}$.

In our study, the sensitivity was even lower indicating that laboratory evidence of coagulopathy still remains the best way to assess the need for ASV. Similarly, a study from Sri Lanka showed that the 20 min WBCT was not only having very low sensitivity $(40 \%)$ but also its performance also led to delay in ASV administration ${ }^{22}$. These observations highlight the fact that in a hospital setting where coagulation studies are easily available, the use of $20 \mathrm{~min}$ WBCT is not only a source of delay in clinical decision making but may also inaccurate because of lack of objectivity in the interpretation of results.

Species identification was possible in only 17 $(37 \%)$ cases. Of these 16 were found to be Saw Scaled Viper or Echis carinatus and only one was Russel Viper. This finding correlates with the fact that majority of the bites in our region are by viper snakes and hemotoxicity is the predominant clinical manifestation. Most common complication was coagulopathy followed renal failure and respiratory failure ${ }^{23}$.

Another important aspect of study is the finding regarding $20 \mathrm{~min}$ WBCT which is widely employed to guage the degree of coagulopathy and as an indication for ASV administration. However, this study showed that it has a very low sensitivity and specificity. The uselessness of the test is also evident from the ROC curve analysis.

Polyvalent liquid ASV from NIH-Islamabad Pakistan was used to treat all patients with features of envenomation. All the patients received ASV within 4 hours of reaching hospital with the an indication for administration. Majority of the patients recovered with 10 vials $25(54.3 \%)$ whereas higher doses were required in 10 patients only $10(21.7 \%)$. This finding is consistent with a study in Pakistan which showed that majority of the patients need up to 10 vials to reverse coagulopathy ${ }^{20}$. In a study from Bangladesh in which majority of the snakebites were due to neurotoxic snake, the average dose of ASV was 10 vials.

Adverse reaction to ASV is however, in our study no major adverse effect like anaphylaxis occurred. Only $17(37 \%)$ patients had minor reactions which were managed by slowing the infusion rate and symptomatic support. In a study from Bangladesh, up to $60.5 \%$ patients experienced adverse effects due to ASV. The lower rate in our study is most likely attributable to premedication with antihistamine and hydrocortisone.

The mortality in our study was $6.5 \%$ which is less as compared to the studies published from other countries. In our region this can be explained by the fact that ASV was readily available and was administered in a timely fashion. This is not the case in majority of far off areas where most of snake bite victims are treated and ASV is available in limited quantities only. 


\section{Blood Clotting Time in Patients of Snakebite}

\section{CONCLUSION}

Snakebite is a common occupational hazard in all regions of Pakistan. This study shows that majority of the bites in Kohat and surrounding areas are of hemotoxic type and saw-scaled viper is the most commonly identified culprit. The use of $20 \mathrm{~min}$ WBCT cannot only be misleading but also a source of delay in administering ASV given the low sensitivity and specificity and high false negative rate. Thus, 20 min WBCT should not be relied upon in clinical decision making especially in the hospital setting where more objective tests of coagulopathy (i.e. PT, PTTK) are available. The timely use of ASV is not only safe but also effective in preventing morbidity and mortality.

\section{Conflict of Interest: None.}

\section{Authors' Contribution}

HJ: Main corresponding, TBT: Supervision of data, AR: Data analysis, SM: Data analysis, RJ: Data analysis.

\section{REFERENCES}

1. Ralph R, Sharma SK, Faiz M, Riberio I, Rijal S. The timing is right to end snakebite deaths in South Asia. BMJ 2019; 364(2): k5317.

2. Longbottom J, Shearer FM, Devine M, Alcoba G, Chappuis F, Weiss D, et al. Vulnerability to snakebite envenoming: a global mapping of hotspots. Lancet 2018; 392(10148): 673-84.

3. Khan M. The Snakebite Problem in Pakistan. Chicago Herpetol Bulletin 2014; 49(12): 165-167.

4. Mahmood K, Naqvi IH, Talib A, Salkeen S, Abbasi B, Akhter T, et al. Clinical course and outcome of snake envenomation at a hospital in Karachi. Singapore Med J 2010; 51(4): 300-308.

5. Chauhan V. The North-South divide in snake bite envenomation in India. J Emerg Trauma Shock 2016; 9(4): 151-154.

6. Hiremath V, Yariswamy M, Nanjaraj AN, Joshi V, Suvilesh KN. Differential action of Indian BIG FOUR snake venom toxins on blood coagulation. Toxin Rev 2013; 33(1-2), 23-32.

7. Rajeswari GK, Suneetha O. A study on whole blood clotting test vs international normalized ratio with whole blood clotting test in management of hemotoxic snake envenomation in a tertiary care hospital, Guntur. IOSR J Dent Med Sci 2019; 18(8): 15-21.

8. Biradar MV, Abhange R. A study of laboratory parameters prothrombin time and 20 minute WBCT in snake bite patients. Medplus-Int Med J 2015; 2(10): 697-701.

9. Harshavardhana HS, Pasha I, Prabhu NC, Amira, Ravi P. Snake bite induced coagulopathy: a study of clinical profi le and predictors of poor outcome. Int J Sci Stud 2014; 2(1): 2-5.
10. Mukherjee AK, Kalita B. A proteomic analysis of Pakistan russelli venom and assessment of efficacy of Indian po-lyvalent and monovalent antivenom. J Proteomics 2016; 144(1): 73-86.

11. Bhaumik S. Problems with treating snake bite in India. BMJ 2016; 352(2): i103.

12. World Health Organization. Guidelines for the management of snakebites. $2^{\text {nd }}$ ed, (p 101-102). India. Publishing and Sales, World Health Organization, Regional Office for South-East Asia; 2016, [Internet] Available at: https://apps.who.int/iris/handle/ $10665 / 249547$

13. Hafezi G, Rahmani A, Soleymani M, Nazari P. An Epidemiologic and Clinical study of snake bites during a five-year period in Karoon, Iran. Asia Pac J Med Toxicol 2018; 7(1): 13-16.

14. Zamani F, Dehdari T, Ahmadi K, Taghi-Rahdari M, Ashrafi A, Babaei A. Investigation of temporal pattern of scorpion sting and snakebite incidence in patients referred to Masjedsoleiman's main hospital. J Saf Promot Inj Prev 2014; 1(4): 190-197.

15. Alam MT, Wadud MA, Islam MMSU. A Study of Snake Bite Cases in Faridpur Medical College Hospital, Faridpur. Faridpur Med Coll J 2014; 9(1): 32-34.

16. Dehghani R, Rabani D, Panjeh Shahi M, Jazayeri M, Sabahi Bidgoli M. Incidence of Snake Bites in Kashan, Iran During an Eight Year Period (2004-2011). Arch Trauma Res 2012; 1(2): 67-71.

17. Rahman R, Faiz MA, Selim S, Rahman B, Basher A, Jones A, et al. (2010) Annual Incidence of Snake Bite in Rural Bangladesh. PLoS Negl Trop Dis 2010; 4(10): e860.

18. Monzavi SM, Dadpour B, Afshari R. Snakebite management in Iran: Devising a protocol. J Res Med Sci 2014; 19(2): 153-63.

19. Qureshi H, Alam SE, Mustufa MA, Nomani NK, Asnani JL, Sharif M. Comparative cost and efficacy trial of Pakistani versus Indian anti snake venom. J Pak Med Assoc 2013; 63(9): 1129-32.

20. Benjamin JM, Chippaux JP, Sambo T, Massougbodji A. Delayed double reading of whole blood clotting test (WBCT) results at 20 and 30 minutes enhances diagnosis and treatment of viper envenomation. J Venom Anim Toxins Incl Trop Dis 2018; 24(1): 14-18.

21. Indira $R$, Fathima $S$, Dhammika $M D$, Nicholas $A B$, Kalana $M$, Geoffrey KI. Performance of the 20-minute whole blood clotting test in detecting venom induced consumption coagulopathy from Russell's viper (Daboia russelii) bites Thromb Haemost 2017; 117(3): 500-507.

22. Isbister GK, Maduwage K, Shahmy S, Mohamed F, Abeysinghe C, Karunathilake H, et al. Diagnostic 20-min whole blood clotting test in Russell's viper envenoming delays antivenom administration. QJM 2013; 106(10): 925-932.

23. Park KH, Shin H, Kang H, Kim C, Choi HJ. Effectiveness of repeated antivenom therapy for snakebite related systemic complications. J Int Med Res 2019; 47(10): 4808-4814. 